\title{
Ousadia e redenção: o Instituto de Pesquisa Histórica de José Honório Rodrigues
}

\author{
Boldness and redemption: José Honório Rodrigues' Institute of \\ Historical Research
}

\author{
Andre de Lemos Freixo \\ andredelemos@gmail.com \\ Pós-Doutorando \\ Pontifícia Universidade Católica do Rio de Janeiro \\ Rua Marquês de São Vicente, 225 - Gávea \\ 22453-900 - Rio de Janeiro - RJ \\ Brasil
}

\section{Resumo}

Este artigo analisa um "futuro pretérito": o Instituto de Pesquisa Histórica (IPH), idealizado por José Honório Rodrigues entre meados da década de 1940 e inícios de 1950. Trata-se de um horizonte não concretizado. Em meio às tensões que marcaram o processo de constituição de uma historiografia profissionalizada no país, o IPH visava inaugurar uma nova fase da história no Brasil. Esse lugar social e institucional centralizaria quase todas as etapas da produção de conhecimento histórico, concorrendo, inclusive, com as Faculdades de Filosofia no que toca à pesquisa e formação de historiadores. Avalio aqui sua proposta bem como o que estaria em jogo para seu idealizador no momento em que formulou seu projeto.

\section{Palavras-chave}

José Honório Rodrigues; Tempo histórico; Historiografia brasileira.

\begin{abstract}
This paper analyzes a "future past": the Institute of Historical Research (IPH), designed by José Honório Rodrigues between the mid-1940s and early 1950s. The Institute is an unaccomplished horizon. Amid the tensions that marked the making of a professionalized historiography, the IPH aimed at becoming the landmark of a decisive turnaround to inaugurate a new phase in the Brazilian History. This social and institutional place would centralize almost every step in the making of historical knowledge in Brazil, to the point of competing with the schools of philosophy in terms of research and in the training of historians. I evaluate here its proposal and what was at stake for its idealizer when he formulated the project.
\end{abstract}

Keywords

José Honório Rodrigues; Historical time; Brazilian historiography.

Recebido em: 19/10/2012

Aprovado em: 27/2/2013 
[...] O grande historiador constrói o mundo espiritual que começa nele de maneira indissolúvel. A vida, de cuja compreensão ele se apropriou, torna-se imediatamente uma força presente e formadora de futuro.

Eduard Spranger ${ }^{1}$

As décadas de 1940 e 1950 configuram um período pouco estudado da trajetória de José Honório Rodrigues (1913-1987). Trata-se de um intelectual que atravessou e participou vivamente de boa parte dos debates historiográficos no Brasil entre 1936 e 1986, aproximadamente, quando um derrame cerebral reduziu muito suas atividades, levando-o a vários problemas de saúde que culminaram no seu falecimento, em abril de 1987 (RODRIGUES; MELLO 1994, p. 25). Assim, não é nada fácil "contextualizar" sua obra. ${ }^{2}$ Pois foram muitos os contextos que atravessou e, sem dúvida, com os quais dialogou ao longo de sua produção intelectual. É importante notar que os horizontes e projetos de Rodrigues mudaram com os anos e isso se reflete nos seus textos, ${ }^{3}$ mesmo aqueles que mantiveram os mesmo títulos. ${ }^{4}$

Ao longo de sua trajetória intelectual o próprio José Honório operou cuidadosa reconfiguração do sentido de seus projetos, especialmente aqueles que não concretizaram o que ele planejara. Pode-se perceber isso, em especial nas edições de Teoria da história do Brasil (1957; 1969; 1978), A Pesquisa histórica no Brasil (1969; 1978; 1981) e História da história do Brasil (1978; 1988). Ana Luiza Marques observa que estes textos buscavam criticar a longa (e até então vitoriosa, pensava o autor) tradição "conservadora" do pensamento histórico brasileiro, enquanto conhecimento social e científico, oferecendo um conjunto de referenciais teórico-metodológicos que contribuiriam para a revisão destas interpretações acerca da história do Brasil. Ao lado de suas novas publicações e estudos, os prefácios, apêndices e posfácios às novas impressões de textos como aqueles, José Honório mantinha-se engajado nos debates acerca da escrita histórica no Brasil e atualizava suas críticas e projetos, cujo alvo seria esta "tradição conservadora" no pensamento histórico do país (MARQUES 2000, p. 77).

Como Glezer avaliou, para José Honório Rodrigues era fundamental que os historiadores conseguissem superar o maior problema da historiografia brasileira e realizassem a integração entre a historiografia e a história (GLEZER 1976, I, p. 76). Como apresento a seguir, trata-se de uma constante nos textos de Rodrigues desde meados da década de 1940. Essa constante residia no fato de que ele sempre procurou manter seus diálogos com os intelectuais contemporâneos assim como com a juventude historiadora, especialmente nas Faculdades de Filosofia. Renovar a formação dos historiadores, também nesse sentido, poderia ajudar na superação dos entraves e obstáculos. Esses diálogos frutificaram. Posteriormente, a partir das turbulentas décadas de 1960 e 1970,

\footnotetext{
${ }^{1}$ Citado por José Honório Rodrigues (RODRIGUES 1953, p. 138).

2 O esforço mais sistemático nesse sentido é a tese de doutorado de Raquel Glezer (GLEZER 1976, I, p. 62-67).

3 Opto aqui pela terminologia "textos", pois analiso escritos de natureza diversa, produzidos por Rodrigues entre 1944 e 1952. Trata-se de artigos para jornais, resenhas, correspondência e, claro, suas publicações, tanto no Brasil quanto no exterior, em formato de livros. Sobre isso, ver: DARNTON 2005, p. 21-27.

${ }^{4}$ Sobre isso, ver: FREIXO 2011, p. 144-146.
} 
jovens historiadores se apropriaram de suas ideias combatentes para pensar sobre história e historiografia em tempos sombrios - em recepções marcadas por suas próprias idiossincrasias e historicidade. Manoel Salgado Guimarães apresentou que essa geração de historiadores da história do Brasil - entre os quais destacou e analisou os textos de Carlos Guilherme Mota, José Roberto Amaral Lapa e Nilo Odália -, desempenhou importante papel na definição de um lugar para Rodrigues na história da historiografia brasileira. ${ }^{5}$ Além disso, podem-se estabelecer relações entre essa recepção e a paulatina configuração de (e embates por) "memórias" para a história e a historiografia brasileira. Assim como a cristalização do nome de Rodrigues como "pioneiro" e referência central nesse sentido, o que atravessa as leituras de outras gerações de historiadores no país (GUIMARÃES 2005, p. 32-35).

As análises de Guimarães, Gontijo e Marques fornecem valiosos elementos para que se problematizem as paulatinas transformações dos textos de Rodrigues, inicialmente destinados à ação na sociedade, com intenções, projetos e horizontes específicos, em uma coerente "obra historiográfica" (GONTIJO 2011 , p. 288) que teve nele próprio, ao longo dos anos, um de seus principais responsáveis. Rebeca Gontijo assevera que os próprios esforços de Rodrigues na configuração de uma tradição, mescla entre memória e história da disciplina, podem ser lidos também como estratégias de constituição identitária. Em sua avaliação, a obra historiográfica de José Honório visava estabelecer seu próprio lugar na memória, ou "panteão" (GUIMARÃES 2005, p. 38), da disciplina no país 142 (GONTIJO 2011, p. 287).

Em diálogo com estes estudos, meus esforços aqui estão em devolver aos textos de Rodrigues seus projetos quanto ao futuro - em seus horizontes primordiais. Analiso a seguir as propostas de José Honório Rodrigues para a fundação do Instituto de Pesquisa Histórica no Brasil entre 1945 e 1952. Para isso, divido o presente artigo em duas partes e um encerramento. Na primeira parte, apresento os horizontes iniciais de suas críticas aos estudos históricos no Brasil e como ele as articulava a um programa científico de matrizes alemãs, sintetizado em Teoria da história do Brasil: introdução metodológica (1949). Isto é, o que o levou a se dedicar à história da história do Brasil pertencia ao conjunto de reflexões acerca da história no Brasil, um esforço para redimensionar não apenas sua importância como saber acadêmico, mas também sua necessidade para a orientação da vida e das ações dos homens (historiadores, inclusive) no seu presente. $\mathrm{E}$, na segunda parte, relaciono a proposta do IPH, publicada em $A$ pesquisa histórica no Brasil: sua evolução e problemas atuais (1952), a aquele programa científico, destacando seu papel central na compreensão de Rodrigues para os rumos (históricos) da história no país.

Como já antecipei, numa obra de tamanho vulto, indago acerca de alguns sentidos que esmaeceram ao longo do tempo. Por isso procurei as edições originais de Rodrigues. Identifiquei, de fato, que se tratava de textos 
relativamente esquecidos em detrimento das reedições, profundamente alteradas e aumentadas pelo autor ao longo de sua vida. Inclusive, é possível perceber nesses textos originais as perspectivas de um autor já bastante engajado, ${ }^{6} \mathrm{o}$ que nem sempre foi lido como traço dos mais louváveis do autor (IGLÉSIAS 1988 , p. 56). Isto é, José Honório não escondia suas posturas críticas nem as expectativas quanto às transformações que ele sugeria como necessárias para renovar a historiografia brasileira. Assim, um dos objetivos deste artigo é articular "com-textos" de Rodrigues, como meio de compreender seus horizontes e projetos nos debates historiográficos nos quais ele procurava se inscrever entre 1945 e 1952,7 reforçando a questão da mudança, bem como perceber como ele combatia em prol de suas convicções e pretensões. ${ }^{8}$

Defendo que seu Instituto representava mais do que um sonho ou mera ousadia. Tratava-se do ponto mais alto de suas expectativas à época acerca do desenvolvimento da história da história do Brasil. Deste modo, é crucial compreender como Rodrigues compreendia essa história e, mais ainda, perceber como esse entendimento configurava uma das matrizes centrais do seu projeto para o IPH, consistindo em críticas engajadas aos debates acerca da necessidade de transformação e renovação dos estudos históricos brasileiros.

Outro ponto fundamental de minha análise reside no fato de que Rodrigues inscrevia sua expectativa crítica, seu engajamento de ação e renovação, na esteira de uma tradição. Torna-se, pois, central compreender o que tradição significava para ele. Bem como avaliar o papel central deste conceito nas suas argumentações em defesa da necessidade do seu projeto para o Brasil. Seus esforços para alinhar presente, passado e futuro dos estudos históricos brasileiros inscrevem-se em uma trama que tinha por finalidade oferecer um meio seguro de orientação no tempo. ${ }^{9}$ Ou seja, Rodrigues buscava a constituição de um sentido, para seus leitores, sobre a experiência do tempo. Sua tradição era o modo como ele articulava essa experiência em termos da pesquisa e escrita histórica no Brasil.

\footnotetext{
${ }_{6}^{6}$ Para Rüsen, na esteira de Karl-Ernst Jeismann, "engajamento" significa vida prática (praxis), "realização da própria existência na luta social pelo reconhecimento, na adoção e na defesa das próprias convicções, na efetivação das pretensões subjetivas de validade, no exercício do poder ou na inserção nele, na participação nos processos culturais que determinam o próprio eu, a relação aos demais, $[\ldots]$, em tudo, enfim, a que se refere o termo 'práxis'"' (RÜSEN 2007, p. 102).

7 Glezer investigou a coerência interna dos conceitos articulados na obra de Rodrigues. Entre 1936 e 1957, aproximadamente, ela afirma que os trabalhos teóricos, metodológicos e historiográficos de José Honório seriam mais informativos do que analíticos. As características principais das obras informativas, ou de "nível descritivo", como analisou, "são o alheamento da figura do autor, a não participação na apresentação do estudo, o afastamento como individuo do processo explicativo, praticamente deixando as informações históricas falarem por si mesmas" (GLEZER 1976, I, p. 67).

${ }^{8}$ A obra de Rodrigues ainda carece de um trabalho que compreenda criticamente as transformações, entre continuidades e rupturas, do pensamento do autor. Tal investimento terá de problematizar a construção da identidade entre escrita (autor), impressos (diferentes edições de livros) e leituras acerca dos textos de Rodrigues. Procurei, aqui, ater-me aos textos e intenções do autor nas décadas de 1940 e 1950 . Analisar as diferentes edições implicaria, também, em uma história dos livros de José Honório, dos impressos sob sua assinatura. Creio ser igualmente fundamental historicizar as muitas apropriações realizadas por agentes em tempos e lugares distintos, atendendo a objetivos e finalidades diferentes.

${ }^{9}$ Articulo aqui as reflexões de R. Koselleck, P. Ricœur e Jörn Rüsen. Trata-se de pensar a configuração do tempo histórico moderno, a partir das narrativas historiográficas, como meio de fornecer uma orientação prática da vida humana. Ver: KOSELLECK 2006, p. 305-327; RÜSEN 2001, p. 76-93; 149-174; 2007, p. 95120; RICEUR 2007, p. 309-320; 2010b, p. 353 et seq.
} 


\section{A emergência do novo}

Em 1939, José Honório Rodrigues ingressou no Instituto Nacional do Livro (INL), onde trabalhou como assistente de Sérgio Buarque de Holanda, na Seção de Publicações. ${ }^{10}$ Rodrigues também escrevia para diversos periódicos articulando críticas ao "estado atual" dos trabalhos históricos publicados no país à época. Apesar da pouca idade, suas críticas estabeleciam e reiteravam vínculos com a postura de um conjunto de intelectuais que se fortalecia no período. Além de Buarque de Holanda e Augusto Meyer, o grupo contava, entre idas e vindas, com Gilberto Freyre, Otávio Tarquínio de Sousa, Willian Berrien, Rubens Borba de Moraes, Caio Prado Junior, Alice Canabrava, entre outros. Eles representavam as vozes da especialização e um "novo espírito historiográfico", exatamente por assumirem "o passado como algo dotado de complexidade, no qual buscavam penetrar, procurando relacioná-lo com o presente" (GONTIJO; FRANZINI 2009, p. 148).

Em um encontro com W. Berrien no Rio de Janeiro, em 1943, José Honório recebeu um convite para estudar nos Estados Unidos da América (EUA). As viagens para os EUA eram constantes entre os intelectuais do círculo intelectual que idealizou o Handbook of brazilian studies (MORAES; BERRIEN 1949, p. 10). ${ }^{11}$ José Honório viajou em 1943, na condição de técnico do INL, para o refinamento de saberes ligados à seleção e preparo de documentos raros para edições críticas e bibliografias especializadas. O Instituto visava preparar seus técnicos para o trabalho de lançamento de documentos inéditos e a elaboração de instrumentos de referência e consulta para pesquisadores da história do Brasil. Rodrigues aproveitou a oportunidade para cursar também a disciplina de Introdução aos estudos históricos, ministrada por Charles C. Cole e outros professores na Universidade de Columbia (RODRIGUES 1945a, p. 16).

Em 1944, Rodrigues retornou ao país entregando a Meyer seu relatório de pesquisas. No relatório, a imensidão dos acervos visitados e sua organização sistemática tiveram sabor "agridoce" para Rodrigues. Por um lado, o fato de estarem prontas para atender às necessidades mais eruditas ou pragmáticas de consulta ao seu conhecimento acumulado sobre diversas culturas do mundo inteiro, inclusive a brasileira, era inspirador. Mas, por outro lado, o jovem historiador convenceu-se de que os problemas dos arquivos e bibliotecas brasileiros seriam ainda muito piores do que ele imaginara. Alegava que no que se referia aos estudos históricos, o Brasil estava "atrasado" em relação aos EUA em pelo menos cinquenta ou sessenta anos (RODRIGUES 1945a, p. 16). Assim, não era

\footnotetext{
${ }^{10}$ Sua entrada se deve a dois fatores: $1^{\circ}$ ) a desistência de José Antônio Gonçalves de Mello Neto - originalmente contratado para o cargo; e $2^{\circ}$ ) reconhecimento de seu esforço como pesquisador dos "holandeses no Brasil", em especial no período de Maurício de Nassau. Esses fatores estavam ligados ao fato de Gilberto Freyre ter intervido junto a Augusto Meyer, o Diretor do INL (MELLO NETO 1951, p. 6).

11 Originalmente em preparo desde 1939, o Handbook foi cercado de problemas e atrasos, em parte devido à Segunda Guerra Mundial, mas também por conta dos autores convidados, em especial os da seção história (RODRIGUES 2004, p. 143-150). Seus organizadores optaram, pois, por publicá-lo em partes, inicialmente em inglês e em capítulos, pelo Handbook of Latin American studies (Harvard University Press). Apenas em 1949 foi publicado em português e no Brasil, sob o título Manual bibliográfico de estudos brasileiros, pela Gráfica Editora Sousa (MORAES; BERRIEN 1949, p. 16-18).
} 
possível ter confiança em documentos editados sem crítica de texto nem em livros raros publicados fora das regras da edição crítica. História sem documentos autênticos e sem edição crítica de fontes primárias não pode merecer confiança nem respeito, nem se pode dar um desenvolvimento aos estudos históricos no Brasil sem a introdução dos modernos processos adotados nos países mais adiantados. O mesmo se pode dizer da necessidade inadiável e urgente da cadeira de introdução à história, até hoje inexistente no currículo das universidades brasileiras (RODRIGUES 1945a, p. 20).

A partir de então, José Honório asseverou críticas como essas em seus artigos, mormente, publicados em O Jornal. Dois deles chamam a atenção, pois avaliavam o estado dos estudos históricos no Brasil, não apenas as publicações, mas seus autores também. Intitulam-se "A historiografia brasileira em 1945" e "A historiografia brasileira em 1946". A parte essencial desses textos se resume ao "exame da metodologia seguida pelos seus autores" (RODRIGUES 1946 , p. 1). Em ambos, Rodrigues separava os autores que representariam o novo espírito crítico brasileiro daqueles que seriam os reflexos do atraso que estagnaria a pesquisa histórica no país. Sua conclusão não era nada otimista. Apesar dos "bons exemplos" que ele identificou em trabalhos de Gilberto Freyre, Sérgio Buarque de Holanda, Otávio Tarquínio de Sousa e Padre Serafim Leite (não obstante algumas ressalvas), suas críticas estabeleciam que os estudos históricos no Brasil não poderiam ficar dependentes única e exclusivamente das interpretações 'livres', que ele avaliou ser a maioria dos casos nas publicações históricas no ano de 1945.12

Assim, Rodrigues marcava uma separação entre a "verdadeira" e a "falsa" historiografias a partir de critérios técnicos e epistemológicos. A "verdadeira historiografia reúne em uma só pessoa as duas figuras que coexistem [separadamente] apenas em historiografias ainda em fase de crescimento". Isto é, o valor da historiografia moderna, inclusive a qualidade e seu grau de amadurecimento, residia entre autores que personificassem o pesquisador sério do passado e o intérprete responsável no presente, uma vez que "todo autêntico historiador deve se submeter às duas fases do processo" (RODRIGUES 1946, p. 1).

O artigo de 1947 examinava publicações do ano imediatamente anterior sendo muito mais extenso, pois publicado ao longo de três edições dominicais do suplemento literário de $O$ Jornal. Afiançava ali que o quadro retratado acerca do ano anterior apenas teria piorado (RODRIGUES 1947, p. 1). Rodrigues desejava separar, por assim dizer, o joio do trigo, oferecendo, inclusive, os necessários

\footnotetext{
12 Rodrigues caracterizava como "livres" todas as histórias escritas por pessoas que não realizaram cuidadosa reflexão (teórica) acerca do papel social e da importância cultural da história naquele contexto sociopolítico. Denunciava também os textos que não se balizavam sobre exaustiva pesquisa de documentos inéditos. Cabe lembrar que, à época, a escrita da história não era limitada por fronteiras acadêmicas ou disciplinares. Mesmo aqueles que José Honório reconhecia como contribuições valiosas não possuíam qualquer formação em história, o que sequer existia no Brasil nas décadas de 1920 e 1930, quando eles iniciaram sua vida intelectual. Sobre isso, ver: GOMES 1996, p. 75. Inclusive, grande parte das críticas de Rodrigues, a partir de então, se apoiarão sobre essa questão da necessidade de uma formação superior para os historiadores no Brasil. Razão pela qual ele defendeu que a especialização deveria partir da Universidade brasileira, mas apenas como meio de consolidar e assegurar o estatuto científico da história.
} 
"reparos" sobre os estudos históricos. Entre as medidas que julgava urgentes e que poderiam "libertar e fecundar" a história no Brasil

nada seria superior à inauguração de um curso de Metodologia da História e de Historiografia, que preparasse o futuro historiador no manejo dos fatos achados em documentos novos. O conhecimento dos métodos da natureza da evidência histórica e das ciências auxiliares poderia contribuir decisivamente para o amadurecimento da historiografia brasileira. A publicação integral de documentos inéditos, o conhecimento da evolução da pesquisa, dos seus métodos, da historiografia e o melhor contato com os trabalhos dos grandes clássicos, nossos ou estrangeiros, possibilitariam o preparo de novos historiadores e evitariam o autodidatismo, de tão perniciosos efeitos (RODRIGUES 1946b, p. 7).

Outra sugestão era a fundação de um serviço de coordenação de pesquisas históricas, "nos moldes do Institute of Historical Research inglês, dirigido por um dos mais notáveis historiadores mundiais, A. Pollard" (RODRIGUES 1946b, p. 7), com o fito de que se poupasse trabalho dobrado em levantamentos e análises de documentos iguais, mas encontrados por diferentes pesquisadores. Satisfeitas essas exigências, afirmava finalmente, "prepararíamos a reviravolta da historiografia brasileira" (RODRIGUES 1946b, p. 7). No entanto, sua argumentação de um atraso historiográfico se agravava ainda mais com a leitura que apresentava da "Universidade brasileira" que, para ele, não forneceria a rigorosa formação científica de que o país necessitava. Nesse sentido, Rodrigues iniciou o preparo de Teoria da história do Brasil (1949). ${ }^{13}$

O plano no qual o texto foi organizado o dividiu em dezoito capítulos, que podem ser separados em dois blocos: $1^{0}$ do primeiro ao oitavo capítulo, Rodrigues estabelece diversas reflexões de caráter teórico geral sobre a história: o desenvolvimento da ideia de história e seu estatuto científico (tal como então acontecia nos EUA e na Alemanha), o problema das causas em história, a periodização, os diversos tipos de histórias, além de um capítulo sobre a "certeza histórica"; e $2^{\circ}$ do nono ao décimo sétimo, expõe todo o seu entendimento acerca da metodologia da história, fontes e documentos, disciplinas auxiliares e as críticas exigidas ao trabalho do historiador. O último capítulo, o décimo oitavo, "A compreensão e síntese históricas", é o encerramento da obra. Voltarei a ele mais à frente.

A compreensão de Rodrigues acerca do que era necessário desenvolver para superar o atraso historiográfico no país pautava-se sobre três traços fundamentais que definiriam o historiador "de fato", isto é, o especialista, o intérprete responsável da história: a reflexão teórica; novas metodologias sobre novas fontes; e a compreensão histórica. A tomada de consciência acerca da história da história do Brasil, seus estágios precedentes e seu atual momento

\footnotetext{
13 Rodrigues indicou os seguintes trabalhos como referências para sua Teoria: Lehrbuch der Historischen Methode und der Geschichtsphilosophie, de Ernst Bernheim (1908); Zur Theorie und Methodik der Geschichte, de Eduard Meyer (1910); Introducción al estúdio de la historia, de Wilhelm Bauer (tradução espanhola de 1944); Introduction aux études historiques de Charles-Victor Langlois e Charles Seignobos; Metodologia e crítica históricas, de Zacarias Garcia Villada (1921); Introduction to research in american History, de Homer C. Hockett (1931); e The writing of History, de Frederick M. Fling (1926); entre outros (RODRIGUES 1949, p. 12-13).
} 
e problemas, tornava-se, pois, central. É possível, portanto, identificar ali mais do que mero catálogo de autores e obras. Rodrigues visou fornecer em Teoria (1949) um impulso decisivo para mobilizar a renovação da história no Brasil. Assim, para além da síntese entre reflexão teórica, lições metodológicas e compreensão, cabe verificar também o fio condutor de sua narrativa, a partir do qual construiu o sentido orientador para seus leitores.

Precisamente sobre esse ponto, no segundo capítulo de Teoria, "A palavra história: desenvolvimento da ideia de história", Rodrigues se apropriou das quatro categorias que Ernst Bernheim utilizava para representar as etapas gerais do desenvolvimento da "ideia" de história no tempo: a história narrativa (as crônicas); a história pragmática (magistra vitæ); história genética (ou "científica"); e a história reflexiva (RODRIGUES 1949, p. 24-25). Isso é importante porque José Honório fez uso dessas categorias em sua própria compreensão da evolução da história no caso brasileiro. ${ }^{14}$ Cada fase representava a superação dialética das etapas anteriores.

Em Teoria (1949), Rodrigues ilustrou basicamente as fases científicas dessa evolução, transpondo-as ao cenário pátrio para sugerir que sua etapa mais avançada, a reflexiva, já estava praticamente encaminhada no país. Faltava apenas um investimento mais sistemático de coordenação coletiva desses esforços, até então reduzida às contribuições de poucos indivíduos como Varnhagen, no caso da historiografia oitocentista, e Capistrano de Abreu, na Primeira República. Seu manual procurou sistematizar um instrumento didático para os aprendizes da tarefa de ensino, pesquisa e escrita histórica. Porém, simultaneamente, também configurava uma narrativa que organizava o tempo no qual a emergência desta "nova" etapa se tornaria não apenas possível, mas urgente e necessária.

A partir do capítulo seis, "A periodização na história do Brasil", pode-se perceber como Rodrigues costurou sua trama. O capítulo apresentava que a periodização, a distinção das épocas históricas, era, por definição, e seguindo Ernst Troeltsch, a tarefa mais complexa e evoluída, pois de ordem "filosófica", no ofício historiador. No caso brasileiro, assevera, essa preocupação surgiu entre os quadros do IHGB: nosso "principal estimulador dos estudos históricos" (RODRIGUES 1949, p. 66). Porém, alertava Rodrigues, nenhum dos seus primeiros sócios teria conseguido resolver a questão. Os esforços de Abreu e Lima, Von Martius, Varnhagen, entre outros, apesar de suas inegáveis contribuições, não lograram sucesso em fixar uma periodização satisfatória para a história do Brasil. Para José Honório, nesse quesito, apenas Capistrano de Abreu foi bem sucedido.

\footnotetext{
14 Sua interpretação sobre as duas primeiras "fases" da evolução historiográfica (história narrativa e pragmática) brasileira somente vieram a público em 1957 e 1963, respectivamente, a partir dos dois volumes de Historiografia del Brasil, publicados originalmente apenas no México. No primeiro, expôs as matrizes de sua "historiografia brasileira" a partir dos cronistas seiscentistas. No segundo, além de alguns cronistas, destacou os textos de eclesiásticos como Padre Antônio Vieira, para quem "a história tem uma finalidade pragmática: toda história é mestra da vida" (RODRIGUES 1963, p. 204). Em 1978, Rodrigues reuniu e atualizou os dois volumes (ainda inéditos no Brasil), publicando-os juntos em um único livro. Acrescentou também novas referências que, cronologicamente, se estendiam até o século XVIII. Trata-se do primeiro volume de sua História da história do Brasil, dedicado ao que definia como "historiografia colonial". Sobre esse texto, ver: MARQUES 2000, p. 40 et seq.
} 
Por sua "agudeza e capacidade crítica", avaliava. Mas também porque Capistrano foi quem melhor sentiu "a necessidade espiritual de buscar" - sem descuidar dos métodos críticos da pesquisa histórica -, "as raízes de nossas verdadeiras épocas, distintas, únicas, singulares", e segundo "motivos econômico-sociológicos" atuais (RODRIGUES 1949, p. 72). Varnhagen, por sua vez,

[...] soube escavar documentos, demonstrar-Ihes a autenticidade, solver enigmas desvendar mistérios, revelar uma multidão de fatos. Compreender, porém, tais fatos em suas origens, em sua ligação com fatos mais amplos e radicais de que dimanam, generalizar as ações e formular-lhes a teoria, não conseguiu nem consegui-lo-ia. Foi essa incapacidade teórica de Varnhagen que o impossibilitou de realizar, na obra mais completa da historiografia brasileira, uma bem planejada e bem arquitetada divisão de períodos. Varnhagen obedeceu quase que exclusivamente a cronologia, a que todos obedecem, mas sem periodizar (RODRIGUES 1949, p. 72).

Rodrigues tratava da questão da periodização da história do Brasil como problema de natureza teórica, marcando-a como algo que estaria além das capacidades dos metódicos pesquisadores oitocentistas. Sintetizava, no mesmo investimento, as contribuições que davam movimento à sua história da história, isto é, que organizavam um sentido no tempo, como exemplificado no caso "Capistrano-Varnhagen". Com isso, construiu sua própria compreensão para o amadurecimento historiográfico nacional cujo sentido apontava na direção da teoria. A figuração de seus "mestres" acompanha as transformações da consciência nesse sentido. Rumo ao novo espírito teórico que seu Capistrano de Abreu ilustrava como o que de mais alto se produziu na historiografia brasileira até (e desde) então: "iniciador e pioneiro, mestre e guia", o fundador de uma nova etapa, que a ciência da história jamais atingira nos oitocentos. Graças a sua intuição "filosófica" (RODRIGUES 1949, p. 78), sua consciência mais evoluída da história, Capistrano tornava-se, pois, o historiador reflexivo por excelência. Crítico de seus predecessores, porque consciente de seu lugar e contribuição para o desenvolvimento e aperfeiçoamento da compreensão da história do Brasil.

Cabe lembrar que Teoria, publicado em 1949, buscava posicionar-se nos debates acerca da importância (ou não) da história para o mundo contemporâneo. Os problemas enfrentados pelo mundo após dois conflitos mundiais colocavam a história em posição difícil frente às ciências como a Sociologia, a Economia e a Antropologia, por exemplo. As histórias nacionais fizeram do passado fonte de "munição ideológica" quase inesgotável para as duas Guerras Mundiais que o mundo ainda tentava se recuperar. Rodrigues, contudo, defendeu ser imperiosa a necessidade de enveredar pelas diferentes reflexões da teoria da história como meio de elaborar novas questões que justificavam a importância da história, ao lado de outras, também como ciência ancorada no presente. ${ }^{15} \mathrm{E}$ não bastavam mais (ou não

\footnotetext{
15 Em maio de 1945, Rodrigues travou um breve debate com seu amigo Evaristo de Morais Filho, em suas colunas quinzenais no suplemento literário e cultural d'O Jornal. Evaristo publicou o artigo "O Brasil e o perigo do historicismo", em 20 de maio, no qual defendeu a Sociologia como a ciência que extirparia de uma vez todas as mazelas que a historiografia "historicista" rendia ao país. Para ele, os historiadores recorriam ao passado como fuga aos dilemas do presente. Rodrigues, por sua vez, exatamente uma semana depois de
} 
apenas) os recursos da metodologia e da crítica histórica, tal como exemplificado nos representantes da fase oitocentista de sua "evolução". Novamente citando Bernheim, José Honório assevera: "espírito sem método, não prejudica menos a ciência do que método sem espírito" (RODRIGUES 1949, p. 114).

Assim, Rodrigues iniciava Teoria lançando um problema de natureza teórica: se a história não era mais a mestra da vida, nem biografia político-administrativa da nação, tampouco munição para regimes totalitários, qual era sua importância para o presente naquele contexto específico? Para José Honório era preciso ficar claro que, apesar dos abusos cometidos em nome da história, a historiografia científica tinha enorme relevância, qual seja: formar a consciência histórica. Essa era a dimensão compreensiva que Rodrigues atribuiu como um dos traços fundamentais da nova historiografia brasileira. Em Teoria isso pode ser lido imediatamente antes das seções que definem a importância e os tipos dos métodos e críticas históricas, pois tão importante quanto ambos para ele. Trata-se do oitavo capítulo, "A certeza histórica". A partir de uma analogia entre a história e o direito, Rodrigues defendeu não apenas o estatuto científico da primeira, mas sua necessidade atual como "ciência hermenêutica". ${ }^{16}$ Rodrigues aqui marcou um ponto importante, pois avaliava como estéreis as concepções puramente empiristas e/ou apenas voltadas à descoberta de documentos, fontes e fatos, e que desconsideravam as novas reflexões nascidas no campo histórico ou mesmo nas ciências "vizinhas" à história. Com base nesse raciocínio, a grande inovação defendida por ele residia neste que era "o ato último e decisivo", como ele escreveu, que "é sempre o da interpretação" (RODRIGUES 1949, p. 110111). Em suma, a história,

como ciência hermenêutica, não limita a sua certeza à transcrição de uma informação dada por quem era tido como autoridade. Nem sequer ela se esgota na reprodução de um documento, de uma fonte. Ela exige, tal como qualquer outra ciência, a prova que justifica a certeza da afirmação. A própria palavra prova não é passiva; é a demonstração de uma coisa duvidosa ou controvertida por meio de argumentos legítimos. Assim, o fundamento da certeza histórica é também a prova; mas a pura exibição de um documento não significa nada, como o testemunho não é prova, mas instrumento de prova. A prova convence, o testemunho pode trazer a dúvida, que é o início de toda a sabedoria. O historiador parte das fontes, dos testemunhos, que são apenas meios de prova, cujo ofício, na Casa de Clio, é essencialmente estimulador (RODRIGUES 1949, p. 111-112).

O mesmo se apresenta no último capítulo de Teoria. Depois de todas as seções metodológicas, Rodrigues retoma a questão hermenêutica a partir dos autores que representavam, para ele, a nova fase da história no Brasil. Juntos

Evaristo, publicou seu artigo "História e atualidade", no qual procurava rebater as afirmações de seu colega. Afirmou que historiografia e compreensão do presente não eram duas coisas completamente diferentes. Defendeu também que o compromisso da história era com o despertar e o incentivar da consciência histórica nas sociedades contemporâneas, assim como a defesa da percepção da mudança e das transformações no tempo. Ver: MORAIS FILHO 1945, p. 1; RODRIGUES 1945b, p. 1.

${ }_{16}$ As matrizes teóricas e filosóficas de Rodrigues, citadas em Teoria (1949), são: DILTHEY 1944a; 1944b; HEGEL 1946; RICKERT 1937; TROELTSCH 1928; WINDELBAND 1903; HUIZINGA 1943. Além dos autores da tradição alemã, Rodrigues citava também: CROCE 1942; s.d.; GASSET 1942; 1940; COLLINGWOOD 1946; TREVELYAN 1919. 
na última página de Teoria, Rodrigues arrematava o seu capítulo dedicado à compreensão (e a síntese) histórica com Gilberto Freyre, Sérgio Buarque de Holanda, Otávio Tarquínio de Sousa, Paulo Prado, Capistrano de Abreu e Caio Prado Junior (RODRIGUES 1949, p. 255). Por sua vez, eles também sintetizavam os principais elementos de formação que caracterizavam a "verdadeira" (nova) historiografia brasileira: 1) suas reflexões eram teoricamente consequentes - pois críticos do presente e apoiados sobre as contribuições das ciências "vizinhas" à história; 2) suas pesquisas eram exaustivas e metodologicamente regradas, balizadas sobre documentos inéditos; e 3) suas interpretações, ou sínteses historiográficas, além de muito bem escritas, forneciam meios de redefinir e redimensionar, a partir de outras bases, os rumos do processo histórico brasileiro. Como Raquel Glezer (1976), pode-se dizer que, para Rodrigues, não bastava "saber" a história do Brasil, era preciso também "fazê-la" a partir de um presente consciente de sua contemporaneidade e responsabilidades para com os rumos da mesma.

No último capítulo de Teoria pode-se ler também o "sentido libertador" que definia seu programa científico como "caminho" a seguir. Articulando as contribuições oitocentistas às mais recentes, desde Capistrano até Caio Prado Junior e Sérgio Buarque de Holanda, o programa de Rodrigues surge como esforço sistemático e disciplinar de normatizar a formação de historiadores a partir destas bases. Uma das maiores pretensões de José Honório em Teoria era, pois, torná-la "reflexo" maior (e, simultaneamente, o instrumento catalisador) da ação que lançaria a fase reflexiva da história no Brasil como regra para formação de historiadores no país. A própria ideia de "introdução", que figura no subtítulo da obra, permite remeter a uma inclusão em uma tradição de pesquisadores eruditos e conscientes. Um texto para historiadores, ontem, hoje e amanhã. Ao final do texto, pode-se pensar que Rodrigues desejava que seus leitores pudessem, talvez, reconhecerem-se coletivamente como herdeiros e continuadores dessa mesma história. ${ }^{17}$ Reunindo-se a José Honório, poderiam abraçar seu programa que, como ele afirmou, era "tão claro e lúcido, simples e nobre, [que] tem sido realizado pela mais moderna historiografia brasileira" (RODRIGUES 1949, p. 255) e, assim, revolucionar os rumos da história da história do Brasil frente aos novos problemas e questões econômicas, sociais e políticas das décadas de 1930 e 1940.

\section{A casa (brasileira) de Clio}

Apesar de já indicado em textos anteriores como uma necessidade inadiável para o país, ${ }^{18}$ o IPH foi apresentado como proposta completa apenas na primeira

\footnotetext{
17 Cabe frisar que na nota de número 11 do décimo capítulo de Teoria (1949), Rodrigues anunciava que um estudo de maior fôlego, e de sua autoria, sobre a "Evolução da Pesquisa no Brasil" já estava em preparo (RODRIGUES 1949, p. 286).

${ }_{18}$ Entre 25 de fevereiro e 23 de maio de 1950, Rodrigues fez nova viagem. Desta vez, a convite do Conselho Britânico, foi à Inglaterra na condição de Diretor da Divisão de Obras Raras e Publicações da BN (no cargo desde 1946), para avaliar os documentos de interesse para a história do Brasil presentes naquele país. Graças ao incentivo do Instituto do Açúcar e do Álcool, assim como do Ministério das Relações Exteriores, Rodrigues pode ampliar sua viagem e visitar outras instituições de cultura, além das inglesas. Visitou arquivos e institutos italianos, portugueses, holandeses, franceses e espanhóis. Seu relatório de viagem, publicado em 1950, trouxe além do vasto inventário documental, também as primeiras linhas que figurarão na sua proposta de criação do Instituto de Pesquisa Histórica. Curiosamente, a esta altura, Rodrigues sugeriu que o IPH fosse
} 
edição de A pesquisa histórica no Brasil, de 1952. Rodrigues aprofundou e direcionou suas críticas anteriores, ainda a partir do cenário dos problemas no que tocava à pesquisa especializada, a consciência histórica e às instituições de cultura no país.

A situação da pesquisa histórica brasileira continua à mercê da iniciativa e do esforço pessoal de cada estudioso, que deve por si só, sem ajuda, examinar milhares de documentos, alguns de nenhum interesse para a sua tarefa. [...] Não há historiografia amadurecida sem pesquisa [...]. Portanto, para que uma historiografia cresça e se torne adulta é indispensável e urgente facilitar a pesquisa, favorecendo o estudioso com os instrumentos, que são essencialmente os catálogos, índices e bibliografias (RODRIGUES 1952, p. 156-157).

A organização de $A$ pesquisa foi cuidadosamente planejada, pois exposta no Colóquio Internacional de Estudos Luso-Brasileiros, promovida pela Biblioteca do Congresso de Washington, entre 18 a 22 de outubro de 1950. Na seção chamada "Preliminares", o autor define "pesquisa histórica", "documento" e o caráter público que reivindicava para seu projeto. ${ }^{19}$ Além desta, outras duas seções dividem esse texto. Na primeira, Rodrigues expôs um quadro geral dos investimentos de pesquisa histórica de caráter público no Brasil, a partir da fundação do IHGB. Na segunda, apresenta o detalhado projeto para o seu Instituto de Pesquisa Histórica.

Na primeira parte, intitulada "A pesquisa histórica no Brasil, sua evolução", Rodrigues, a partir de 29 pontos, enreda os investimentos de pesquisa de caráter público que, desde a fundação do IHGB, resultaram em contribuições para o avanço das pesquisas históricas, do acervo documental ou mesmo das práticas metodológicas no trato de documentos raros no Brasil.

A pesquisa histórica no Brasil nasceu com a fundação do Instituto Histórico e Geográfico Brasileiro. Em outros países a criação dos Institutos Históricos vem atender ao apelo de vários pesquisadores pelo trabalho de conjunto. Antes existe apenas a pesquisa individual, o trabalho de um ou outro estudioso, que tenta encontrar, em arquivos nacionais ou estrangeiros, peças novas que fundamentem os temas a desenvolver. Mas o gasto de tempo, dinheiro e trabalho que podiam ser economizados por uma melhor organização pública, convidam os pesquisadores a um encontro permanente que os ajude na tarefa preliminar e fundamental do trabalho histórico. Ainda assim, nem sempre os Institutos Históricos atendem a este apelo (RODRIGUES 1952, p. 25).

O momento do surgimento do IHGB, e de seus congêneres estaduais, figurou como o berço de instituições como aquela que Rodrigues almejava implantar no país. Isso porque seus estatutos fixavam, desde 1839, os seguintes objetivos: "coligir, metodizar, publicar ou arquivar os documentos necessários para a história e geografia do Império do Brasil" (RODRIGUES 1952, p. 25). Mas o fundamental não estava só aí. Tratava-se também de iniciativas com "fins universitários", cuja meta se inspirava nos "melhores e mais corretos princípios 
que acabavam de ser lançados pela escola alemã", quais sejam: "investigar, organizar e publicar os documentos históricos brasileiros" (RODRIGUES 1952, p. 25). O Brasil nascia, pois, para o "espírito" da crítica e da metodologia da história: o berço da ciência da história e uma experiência institucional e pública que gozava de grande atualidade para Rodrigues.

Enquanto evolução, a etapa oitocentista superava a anterior - marcada pelos trabalhos dos cronistas ou daqueles que procuravam a história como "mestra da vida" -, distinguindo-se das mesmas exatamente pelo rigor crítico com que trabalharam a partir de pesquisas sobre a documentação original produzida pelos seus predecessores. Mas era igualmente a base para a história renovar-se. Essa atualidade era fundamental. Como Gontijo bem observou, para Rodrigues "o papel do historiador é tanto livrar os homens do presente do peso do passado - por meio da consciência histórica e de uma historiografia crítica -, como conservar o 'legado' necessário para a construção do futuro" (GONTIJO 2010, p. 285). Trata-se da função "catártica da história" (RODRIGUES 1949, p. 22), como Rodrigues a intitulou, claramente inspirado na máxima de Goethe, de que "escrever história é um meio de desembaraçar-se do passado" (GOETHE 2003, p. 30). ${ }^{20}$ José Honório pensava da mesma forma a escrita da História e a escrita da história da história. Assim,

conhecer o que já se fez e propor o que se deve fazer é o objetivo deste trabalho. Atender a este objetivo significa, no Brasil, restaurar a tradição imperial de cultivo da história, tão abandonada pela República, descuidosa do passado e de suas vozes e tão confiante nas tarefas do momento, a tal ponto que o próprio futuro nem sempre foi bem assegurado. O passado só pode ser superado quando suas razões forem ouvidas; de outro modo, ele as reclama (RODRIGUES 1952, p. 11).

A tradição de cultura histórica clamada por José Honório em A pesquisa era composta, mormente, por pesquisadores históricos. ${ }^{21}$ Contudo, sua evolução não seguia uma linha sucessiva de progressos. Pelo contrário, reforçava que a tradição de pesquisadores históricos esmaeceu e enfraqueceu-se, especialmente durante a República. Sua avaliação da necessidade de se fundar no país uma nova instituição, em honra a esta tradição, justificava-se em parte sobre esse argumento. Seu IPH também concorreria - se construído - com a universidade brasileira ou, pelo menos, complementaria seus préstimos de modo a honrar a tradição de cultura histórica que primava pela rigorosa pesquisa documental, mas não apenas. A nova "casa de Clio" deveria centralizar, coordenar e manter poder e autonomia de registro e controle sobre todas as dimensões que constituíam a produção de conhecimento histórico no Brasil. Desde a estrutura

\footnotetext{
${ }^{20}$ A referência de Rodrigues para o texto de Goethe, Maximen und Reflexionen, refere-se à edição alemã das Obras Completas (Sämmtliche Werke) do autor, publicada pela editora J. G. Cotta'scher Verlag, em 1860 (RODRIGUES 1949, p. 259).

${ }^{21}$ Seguia, pois, deste modo: Antonio Meneses Vasconcelos de Drummond, Francisco Adolfo de Varnhagen, Antônio Gonçalves Dias, João Francisco Lisboa, Joaquim Caetano da Silva, Ramiz Galvão, Medeiros e Albuquerque, José Higino Duarte Pereira, F. A. Pereira da Costa, Oliveira Lima, Norival de Freitas, Manuel Cícero Peregrino da Silva, Rodolfo Schuller, Pedro Souto Maior, o Barão do Rio Branco, Joaquim Nabuco, Capistrano de Abreu, o Barão de Studart, Afonso d'E. Taunay, Alberto Rangel, Alberto Lamego, Tobias Monteiro, Jerônimo Avelar Figueira de Melo, Luís Camilo de Oliveira Neto e Pedro Calmon.
} 
básica dos arquivos e seus acervos documentais, estendendo-se até a formação teórica e metodológica de novos historiadores, assim como seus arquivistas e bibliotecários.

A organização fundamental do IPH era relativamente simples. Em termos administrativos, como se pode ver no organograma abaixo, além da Direção, ele se divide em três partes centrais: a Comissão de Pesquisa Histórica no Brasil, a Comissão de Pesquisa Histórica no Exterior e a Comissão de Formação de Pesquisadores. Estes três pilares sustentariam toda a estrutura desta casa para os novos historiadores brasileiros.

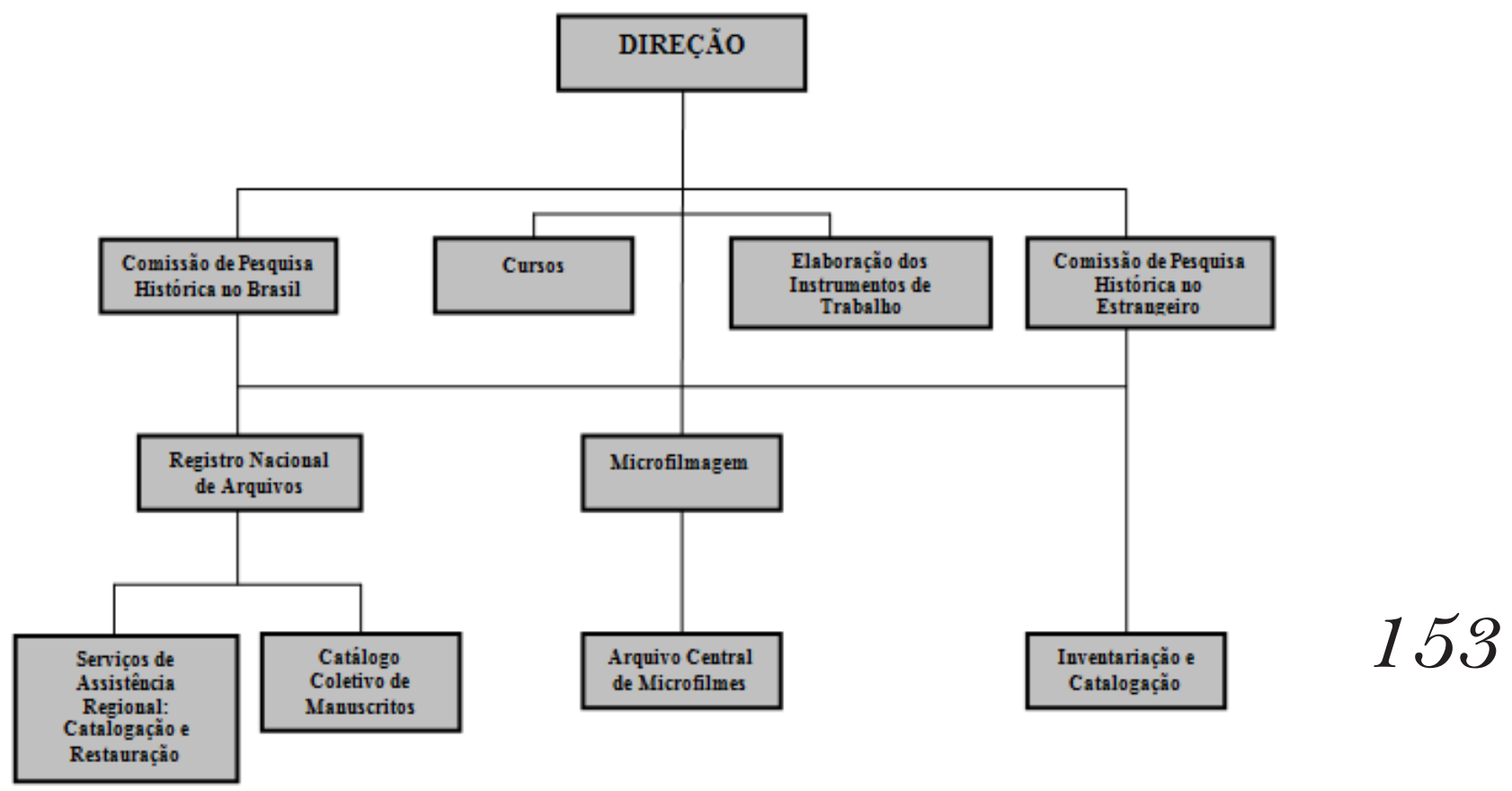

Organização do Instituto de Pesquisa Histórica (RODRIGUES 1952, p. 270).

As duas primeiras organizam e executam a mesma tarefa, apenas com focos distintos. No primeiro caso, em termos internos e, no segundo, fora do país. Rodrigues dava importância equivalente às duas. Mas à primeira cabia todo o cuidado com a preservação dos documentos e a organização dos arquivos brasileiros, o que ele sublinhava ser urgência mais grave, dado o estado da dispersão e a falta de investimentos e instituições que pudessem tratar dos documentos brasileiros (no país ou fora dele) já "em risco de desaparecimento" (RODRIGUES 1952, p. 193). A Comissão nacional ficava responsável, portanto, pela organização de um levantamento nacional de toda a documentação histórica existente no interior do país, em vilas, municípios, e distritos. Do mesmo modo, era encarregada de averiguar o estado geral dos arquivos públicos e particulares, e de investigar em que situações se encontrariam seus acervos. A segunda Comissão, de caráter internacional, coordenaria tudo o que envolvesse a pesquisa histórica fora do país, desdobrando-se num setor de inventários e catalogação dos documentos históricos a serem adquiridos para o acervo de alguma instituição brasileira. 
Após esse trabalho de levantamento da documentação existente no Brasil e no exterior, Rodrigues sugeriu que o processo de cópia, através de "fotomicrofilmagem", fosse implementado. A criação de uma Divisão de Microfilmagem, associada a um Arquivo Central de Microfilmes, também era oferecida como alternativa mais profícua para a preservação dos documentos antigos e raros - todos ameaçados de destruição. O Arquivo de Microfilmes também elaboraria seus instrumentos de trabalho, isto é, a organização de um grande Catálogo Geral de Microfilmes, no qual haveria a indicação dos documentos fotocopiados no Brasil e no exterior, já adquiridos para o país ou não.

A terceira Comissão do IPH ficava encarregada de todo o segmento de ensino superior. Rodrigues propunha fornecer ali a formação que os jovens estudiosos da história do Brasil não encontravam nos "cursos especializados". ${ }^{22}$ Tratava-se também de uma proposta institucional relacionada diretamente com o programa científico de Rodrigues para a História no e do Brasil. Isso se apresentava de modo particularmente claro na questão da formação de historiadores especializados, que estava entre as principais tarefas do IPH. Esse preparo se daria através de seminários e cursos de extensão, ministrados no próprio Instituto. Assim como ele presenciou na Europa e nos EUA, em instituições que the serviram de inspiração para o IPH (RODRIGUES 1950, p. 30-41; 1952, p. 183-192), esses cursos visavam à formação histórica dos jovens licenciados em história. Formá-los não apenas como pesquisadores modernos, mas como herdeiros e sucessores dos grandes intérpretes da história do Brasil. ${ }^{23}$

O programa de curso para essa formação seguiu o exposto em Teoria da história do Brasil (1949). ${ }^{24}$ Rodrigues teve o cuidado de enfatizar que a formação de novos pesquisadores não era apenas uma exigência do IPH. Esse tipo de formação também era o que faltava à capacitação de novos especialistas para todas as instituições de natureza patrimonial e cultural no país. Por isso, o que estava em questão ali era articulado como uma defesa da tradição de cultura histórica. O IPH de José Honório visava centralizar num mesmo lugar todos os diferentes aspectos da produção de conhecimento histórico no país. Quais sejam: 1. reunir os meios para a pesquisa histórica; 2. a formação teórica

\footnotetext{
22 O projeto do IPH também previa organizar um Registro Nacional de Arquivos, responsável pelo mais exaustivo e completo levantamento de conteúdos dos acervos documentais em arquivos do Brasil, fossem eles particulares ou públicos. Rodrigues assevera que esse Registro precisava ter poderes legais de intervenção sobre todos os documentos brasileiros: para localizá-los, registrá-los e catalogá-los (RODRIGUES 1952, p. 203). O inquérito e o registro eram, portanto, meios de "codificar a informação e incorporá-la definitivamente ao patrimônio da nação" (RODRIGUES 1952, p. 202-203). Esse procedimento deveria ser feito em todas as partes do país, fossem arquivos federais, regionais, municipais ou particulares. Campanhas locais e nacionais deveriam acionar os meios de comunicação, como a imprensa local, por exemplo, a convocação de seus concidadãos à cata dos documentos de valor histórico ou mesmo dos papéis aparentemente insignificantes, sendo instruídos sobre a importância da sua conservação (RODRIGUES 1952, p. 205-206).

${ }^{23}$ O temário destes seminários apresentava: Metodologia da história; A pesquisa na história do Brasil; Historiografia brasileira; Disciplinas auxiliares da história; Iconografia; Cartografia; Paleografia e diplomática; Crítica histórica; Crítica de textos; História e historiografia estadual, regional e local; História e historiografia diplomática do Brasil; História e historiografia econômica do Brasil; História e historiografia Militar do Brasil; História e historiografia Social do Brasil; História e historiografia da Arte no Brasil; História e historiografia da Educação no Brasil; História e historiografia ciência no Brasil; História e historiografia da Imprensa no Brasil; História e historiografia intelectual no Brasil; Biografia (técnica, métodos e pesquisa); entre outras (RODRIGUES 1952, p. 235-236).

${ }^{24}$ Ver especificamente os capítulos 11 e 12, "Disciplinas auxiliares da história" e "Disciplinas auxiliares da história (II)" (RODRIGUES 1949, p. 142-181).
} 
e metodológica de pesquisadores e historiadores; 3. a assistência regional aos arquivos públicos e privados e às seções de manuscritos, obras raras e/ou publicações das bibliotecas brasileiras. ${ }^{25}$

Assim, como Marques observou, o Instituto representava o "início de uma renovação historiográfica" (MARQUES 2000, p. 22). Aqui é importante atentar que, apesar de se voltar para o passado, Rodrigues inscreveu suas críticas no presente, porém com vistas ao início de algo que ainda não havia se concretizado. Isto é, avaliava que o estado atual de descaso com as pesquisas históricas, arquivos e bibliotecas públicas, era sintoma de uma crise muito maior, e que poderia ter consequências bastante nocivas para sociedade brasileira - na qual era ainda recente o fim do Estado Novo. A crise dizia respeito ao declínio da consciência histórica na sociedade brasileira. Às posturas, por vezes movidas por interesses políticos, de tornar a história crítica algo dispensável, e o passado apenas um manancial para cultos nostálgicos. Rodrigues defendeu a arquitetura de uma casa na qual se salvariam não só documentos, mas se preservaria a própria cultura histórica e, com ela, os horizontes da historiografia (crítica) brasileira. ${ }^{26}$

O projeto de Rodrigues se posicionava como crítica frontal ao descaso que ele identificava em instituições como arquivos e bibliotecas públicas, assim como as Faculdades de Filosofia (RODRIGUES 1952, p. 191-192). José Honório dizia ser necessário investir em cursos intensivos e seminários voltados aos recém-formados nas faculdades, decididos a "dedicar-se à pesquisa das fontes históricas relativas ao Brasil" (RODRIGUES 1952, p. 228). Além disso, acrescentava, "a Universidade não vem formando pesquisadores e historiadores, mas simplesmente professores de História para o ensino secundário" (RODRIGUES 1952 , p. 229). Se as Faculdades de Filosofia continuavam seu papel de "Escola Normal Superior", prosseguia ele, precisava-se encontrar uma "solução fora dos seus quadros". Esta solução seria o seu Instituto de Pesquisa Histórica. Haveria ali a possibilidade de, ao lado das reflexões teóricas, incentivar e desenvolver pesquisas modernas, sobre fontes inéditas e fomentar a escrita consciente e responsável do passado brasileiro.

\section{Encerramento}

O IPH de Rodrigues, apesar de não ter se concretizado, permite descortinar uma perspectiva em que história e tradição não figuram como "inimigas". ${ }^{27}$

\footnotetext{
25 "Um Instituto de Pesquisa Histórica, tendo como programa a pesquisa erudita, a salvação do precioso legado documentário da pátria ou relativo à pátria e a elaboração dos instrumentos científicos do trabalho histórico, há de contribuir para a construção da nossa própria história, pois o conhecimento de nossas próprias origens é uma condição essencial da arte política e do progresso social, [...]. Há de contribuir, também, para a formação da consciência da nossa tradição, [...]" (RODRIGUES 1952, p. 181-182).

${ }^{26}$ Ou seja, "[...] a criação do Instituto de Pesquisa Histórica se apoiaria na melhor tradição brasileira, pois, no Império, d. Pedro II patrocinou várias pesquisas para a colheita dos documentos espalhados pelas províncias e para a colheita e cópia dos papéis existentes nos arquivos estrangeiros. Os exames feitos nos arquivos provinciais por Varnhagen, Gonçalves Dias, Machado de Oliveira, Pereira da Costa e outros revelaram o descuido, desmazelo e incúria com que se tratavam os papéis históricos naqueles depósitos. [...] o governo Imperial, [...], procurava obter, por intermédio de seus delegados nas províncias, originais ou cópias autênticas dos documentos importantes que existissem tanto nos arquivos das municipalidades como em quaisquer outras repartições ou estabelecimentos, [...]. A iniciativa de tanto interesse foi inteiramente abandonada pela República" (RODRIGUES 1952, p. 175-176).

${ }^{27}$ As críticas à separação entre história e tradição podem ser integralmente redimensionadas a partir das contribuições da hermenêutica filosófica de Hans-Georg Gadamer (2004). No plano da teoria da história, ver: RÜSEN 2012.
} 
Com base no que foi apresentado, pois pode-se abordar o pensamento de José Honório Rodrigues por outras bases, ${ }^{28}$ permite perceber também que há um investimento estético e retórico nos seus textos (RÜSEN 2007, p. 29).

Estético, pois implica uma intenção claramente delineada, manifesta em termos de um efeito irônico que o autor almejava produzir sobre seus leitores, fruto do seu desejo de intervenção na sociedade da qual comparticipava não apenas como autor, mas um agente de transformação histórica. Seus textos visavam conceder ao leitor uma compreensão histórica "catártica", ou seja, libertadora do "fardo do passado", que servia ao impulso do presente para a ação consciente. Assim como também era retórico, pois se trata de um tipo específico de estratégia de convencimento, uma vez que determinada pelas intenções de seu autor, através da escrita de textos de história de e para historiadores. Essa intencionalidade de Rodrigues apresenta-se em sua escrita, dirige-se ao mundo do qual ele pertence e que deseja transformar; inscreve-se na vida prática, pois se relaciona como mediadora entre a experiência narrada e os horizontes perseguidos.

Para dizer como Koselleck, a história como singular coletivo (em seu formato moderno), permite que essa arquitetura seja planejada a partir de uma estrutura temporal bem organizada, na qual o presente se abre como o tempo da ação entre o passado e o futuro. O tempo histórico que Rodrigues organizava fazia de seu presente o instante para preparar a ação renovadora. Tempo no qual se engastava o desenvolvimento das pesquisas que contribuíram para a emergência da historiografia como um campo de especialistas responsáveis no 156 Brasil. Historiografia que, para José Honório, significava algo muito específico. Era um horizonte para a escrita da história no Brasil, mais do que o somatório dos seus trabalhos e trabalhadores. Seu projeto para o IPH estava afinado à compreensão de que o historiador precisava triunfar sobre a tradição sob a pena de fracassar por causa dela. Assim, o que difere essa perspectiva de qualquer investimento simplesmente memorialístico, conservador ou de usos exemplares do passado, como na historia magistra vitæ, por exemplo, pode ser lido a seguir:

[...] não há nenhum passado ao qual se devesse querer voltar: há só um eterno novo que se forma dos elementos ampliados do passado e o desejo autêntico deve ser sempre produtivo, criar um novo melhor. [...] Não se pode querer nunca voltar ao passado, a certo passado que se idealizou por mero romantismo. Há, sim, valores tradicionais que podem e devem ser mantidos, mas sempre ao lado de uma tendência renovadora. Todo aquele que participa da criação do presente e do futuro sente dentro de si duas almas que se contrapõem e se interpenetram: vontade de conservar e vontade de subverter (RODRIGUES 1949, p. 22).

Rodrigues, contudo, não ignorava a contingência histórica, sabia que seus textos eram passíveis de aceitação ou rejeição argumentativa, pois abertos à crítica. ${ }^{29}$ Mas, independentemente disso, essa organização não poderia jamais

\footnotetext{
${ }^{28}$ Guimarães (2005, p. 38) e Gontijo (2010, p. 282) destacam a dimensão teleológica da história da história de Rodrigues.

${ }_{29}$ Talvez pelo fato de não ter logrado sucesso com seu Instituto, assim como a tradição reivindicada por ele, Rodrigues posteriormente pode reconhecer que seu trabalho teve por fito apontar caminhos, sugerir alternativas. Como um "líder", sem dúvida, mas como ele mesmo recordava: "Tudo isso, entretanto, não
} 
estar fora dos horizontes de um intérprete, que, para José Honório, tinha de ser sempre um "verdadeiro" historiador.

O fio condutor de sua compreensão pode ser identificado em Teoria da história do Brasil e em A pesquisa histórica no Brasil, especialmente na sua configuração (narrativa) de um tempo histórico. ${ }^{30} \mathrm{~A}$ trama na qual passado, presente e futuro se articulam nos textos de José Honório é a instância que configura o tempo especificamente histórico no qual o "novo" pode emergir como horizonte. Sua trama apresenta e configura o relacionamento dos eventos que constituem essa orientação no tempo, a partir de um eixo central. A reviravolta que pretendia implantar era parte de sua compreensão histórica. Rodrigues incorporava-se na história ali apresentada que, por sua vez, era entendida por ele como o resultado desse mesmo processo.

Por outro lado, José Honório não escondeu suas expectativas. Sua própria concepção de tradição, ${ }^{31}$ define que a dimensão hermenêutica (a tarefa compreensiva da história) estava inscrita no próprio esforço crítico de interpretação histórica. O recurso ao conceito de tradição era fundamental, pois ele inscrevia-se como parte de um discurso histórico que visava superar uma crise da consciência histórica no Brasil, tal como ele mesmo diagnosticara. Assim, torna-se possível, também, identificar que a tradição que Rodrigues defendeu era profundamente crítica e histórica; uma tradição que se pode chamar de reflexiva. ${ }^{32}$

Sua tradição tinha também um horizonte de leitores no momento em que Rodrigues a organizou. Visava aos jovens estudantes das Faculdades de Filosofia do Brasil, como anunciou em Teoria (RODRIGUES 1949, p. 11). Suas críticas e, em grande medida, a crise da consciência histórica que ele diagnosticava no Brasil e no mundo pós-1945, identificavam na Universidade mais um sintoma do que uma possível solução. ${ }^{33}$ Sua tradição orientava pela promessa de renovação neste cenário de crise, incitava seus leitores à reflexão crítica sobre o que estaria

nos pode levar jamais a rejeitar a ideia de liberdade e a desrespeitar a contingência histórica" (RODRIGUES 1978 , p. 472). Ou seja, seguir o líder é deixar-se convencer pelo que foi dito. Este convencimento é e deveria permanecer sempre no âmbito da liberdade de escolha dos outros. Afinal, dizia ele, no limite, "o que cada um pode fazer é trabalhar com o melhor da sua habilidade para a vinha comum". Contudo, alertava o próprio José Honório: "nenhum historiador, por mais ilustrado que seja, é uma autoridade que devamos seguir cegamente" (RODRIGUES 1978, p. 275).

30 Pode-se seguir com Paul Ricœur que, em Tempo e narrativa, afirmou: "o tempo se torna tempo humano na medida em que é articulado de maneira narrativa" (RICCEUR 2010a, p. 9).

31 Décadas depois, a questão da tradição, ainda segundo os moldes alemães e historicistas, permanecia como elemento fundamental defendido por Rodrigues para a libertação do peso do passado e mobilização não só dos historiadores, como também de todo povo brasileiro, para a ação no presente. Rodrigues dizia que "[...] os historicistas não preconizam qualquer forma de restauração do passado ou de regresso ao passado. Preconizam, pelo contrário, a vinda do passado até ao presente, o desenvolvimento do que nele se continha embrionariamente e a sua complementação com os produtos do discurso humano e da dialética da história" (RODRIGUES 1988, p. 192).

32 Aproprio-me aqui da tipologia proposta por Jörn Rüsen. Na tentativa de formular alternativas aos abusos que muitas vezes são cometidos em nome da "tradição", sem com isso definir claramente de que recurso à tradição se fala, Rüsen propõe distinguir três modos (ou tipos ideais) de tradição: 1. funcional - afirmação inconteste de todas as condições pré-estabelecidas da vida social como se conhece. Normalmente persegue e cultiva com grande estima as origens e as longas continuidades entre passado e presente; 2 . reflexiva - pode ser observada quando o papel da tradição em uma cultura histórica se torna um elemento para redimensionamentos e reformulações analíticas, na qual a tradição assume a forma de parte de um discurso histórico, isto é, passível de aceitação argumentativa e aberto à crítica; 3. "/atente" - são tradições que repousam fundo no inconsciente cultural das sociedades, parecendo esquecidas, mas na realidade estão dormentes e configuram importantes elementos prévios na constituição das culturas humanas, mesmo quando aparentemente esquecidos pelas mesmas (RÜSEN 2012, p. 59, traduções livres. Aspas e grifos como no original).

33 Sobre a dinâmica do desenvolvimento das Ciências Sociais no Brasil, ver: MICELI 1989. 
ao seu alcance neste universo no qual a própria validade da história estava em questão. O que poderia ser almejado, a renovação, somente se daria a partir de uma "responsabilidade", para falar como Johan Huizinga, histórica (HUIZINGA 1980, p. 95). ${ }^{34}$

Mas, se provocava seus leitores a pensar sobre o seu presente, naquele momento específico, sua interpretação fazia-se também histórica. Ou seja, no pensamento de José Honório nada obrigaria que, em outros tempos, outros "presentes", sua interpretação da tradição devesse ser recolhida como ainda válida. Pois cada geração deve interpretar a história à sua maneira, diante das questões próprias do seu tempo. Assim, seus textos, mesmo os de caráter teórico e historiográfico, abriam uma brecha no discurso histórico na qual o intelectual engajado se apresentava como voz ativa na articulação entre experiências e expectativas. Rodrigues explicitava sua indignação em suas críticas, expondo os problemas que identificava nos estudos históricos no Brasil. O efeito estético (ironia) que ele visava produzir sobre seus leitores estava atado a essa condição. Sua tradição reflexiva lançava um convite e uma provocação aos leitores: contrapor-se ao descaso frente à cultura histórica, ou "pecar pela omissão", o que só agravaria o cenário atual se nada fosse feito. Rodrigues visava conscientizar seus leitores a partir deste recurso (quase) prognóstico. Despertar neles, a partir de sua própria reflexão crítica, o desejo de também indignarem-se frente aos problemas e necessidades que atrasavam a efetiva modernização da historiografia brasileira. No limite, seu projeto para o IPH

158 acaba assumindo moldes redentores, como a única salvação diante do quadro de descaso apresentado. Talvez essa tenha sido sua maior ousadia.

\section{Referências bibliográficas}

COLLINGWOOD, Robin G. The idea of history. Oxford: Clarendon, 1946.

CROCE, Benedetto. La historia como hazaña de la libertad. Mexico: Fondo de Cultura Economica, 1942.

. Orientações: ensaios de filosofia política. s.l.: Athena Editora, s.d.

DARNTON, Robert. Discourse and diffusion. Contributions to the history of concepts, n. 1 , v. 1, mar. 2005, p. 21-27.

DILTHEY, Wilhelm. Introducción a las ciencias del espiritu. Mexico: Fondo de Cultura Economica, 1944.

.El mondo historico. Mexico: Fondo de Cultura Economica, 1944.

FRANZINI, Fabio; GONTIJO, Rebeca. Memória e história da historiografia no Brasil: a invenção de uma moderna tradição, anos 1940-1960. In: SOIHET, Rachel [et al.]. Mitos, projetos e práticas políticas: memória e historiografia. Rio de Janeiro: Civilização Brasileira, 2009, p. 141-59.

\footnotetext{
${ }^{34}$ A referência indicada por Rodrigues em Teoria (RODRIGUES 1949, p. 282) refere-se à tradução para o espanhol de El concepto de historia y otros ensaios, porém a partir da primeira edição, realizada pelo Fondo de Cultura Econômica do México, publicada em 1946.
} 
FREIXO, Andre de Lemos. A arquitetura do novo: ciência e história da História do Brasil em José Honório Rodrigues. Tese de Doutorado. Rio de Janeiro: Programa de Pós-Graduação em História Social do Instituto de História da UFRJ, 2012.

. Um "arquiteto" da historiografia brasileira: história e historiadores em José Honório Rodrigues. Revista Brasileira de História, São Paulo, v. 31, n. 62, p. 143-172, 2011.

GADAMER, Hans-Georg. Verdade e método I: traços fundamentais de uma hermenêutica filosófica. 6a ed. Petrópolis, Rio de Janeiro: Vozes, 2004.

GASSET, Jose Ortega y. Historia como Sistema.Revista de Occidente, Madrid, 1942.

. Historiologia. In:

Goethe desde dentro. Buenos Aires, Espasa-Calpe, 1940.

GLEZER, Raquel. O fazer e o saber na obra de José Honório Rodrigues: um modelo de análise historiográfica. Tese de Doutorado. São Paulo: USP, 1976 (2 vol.).

GOETHE, Johann W. von. Máximas e reflexões. Rio de Janeiro: Forense Universitária, 2003.

GOMES, Angela M. de Castro. História e historiadores: a política cultural do Estado Novo. Rio de Janeiro: Editora FGV, 1996.

GONTIJO, Rebeca. José Honório Rodrigues e a invenção de uma moderna tradição.

In: NEVES, Lucia Maria B. P. das. [et al.]. Estudos de historiografia brasileira. Rio de Janeiro: FGV, 2011, p. 276-290.

GUIMARÃES, Manoel Luiz Salgado. Historiografia e cultura histórica: notas para um debate. Ágora, Santa Cruz do Sul, v. 11, n. 1, jan./jun., 2005, p. 31-47.

HEGEL, George W. F. Lecciones sobre la filosofia de la historia universal. Buenos Aires: Revista de Occidente, 1946.

HUIZINGA, Johan. El concepto de la historia y otros ensayos. México: Fondo de Cultura Economica, 1980.

Im Bann der Geschichte: Betrachtungen und Gestaltungen. Akademische Verlagsanstalt Pantheon, Schweizerische Lizenausgabe: Burg-verlag, 1943.

IGLÉSIAS, Francisco. José Honório Rodrigues e a historiografia brasileira. Estudos Históricos, Rio de Janeiro, v. 1, n. 1, 1988, p. 55-78.

KOSELLECK, Reinhart. Futuro passado: contribuição à semântica dos tempos modernos. Rio de Janeiro: Contraponto; Ed. PUC-Rio, 2006.

MARQUES, Ana Luiza. José Honório Rodrigues: uma sistemática teórico-metodológica a serviço da história do Brasil. Dissertação de Mestrado. Rio de Janeiro: PUC-RIO, 2000. 
MELLO NETO, José Antonio Gonçalves de. Bibliografia do Domínio Holandês. Diário de Pernambuco, Recife, 24 jun., 1951.

MICELI, Sérgio (org.). História das Ciências Sociais no Brasil. Vol. 1. São Paulo: Vértice, 1989.

MORAES, Rubens Borba de; BERRIEN, William. Manual bibliográfico de estudos brasileiros. Rio de Janeiro: Gráfica Editora Souza, 1949.

MORAES FILHO, Evaristo de. O Brasil e o perigo do historicismo. Revista (suplemento literário de $\mathbf{O}$ Jornal), Rio de Janeiro, domingo, 20 de maio de 1945, p. 1-2.

RICKERT, Heinrich. Ciencia cultural y ciencia natural. Buenos Aires: Espasa Calpe, 1937.

RICCFUR, Paul. Tempo e narrativa I: a intriga e a narrativa histórica. São Paulo: Martins Fontes, 2010a.

. Tempo e narrativa III: o tempo narrado. São Paulo: Martins Fontes, 2010b.

A memória, a história, o esquecimento. Campinas: Unicamp, 2007.

RODRIGUES, José Honório. História e atualidade. Revista (suplemento literário de O Jornal), Rio de Janeiro, 27 mai. 1945b.

. Uma viagem de pesquisas históricas. Revista do Instituto Histórico

160 e Geográfico Brasileiro, Rio de Janeiro, 134-135: 14-29, jul.-set, 1945a [1946].

. A historiografia brasileira em 1945. Revista (suplemento literário de $\mathbf{O}$ Jornal), Rio de Janeiro, 10 mar. 1946.

. A historiografia brasileira em 1946 (I, II e III). Revista (suplemento literário de O Jornal), Rio de Janeiro, 12, 19 e 25 jan. 1947.

. Teoria da história do Brasil: introdução metodológica. São Paulo: Instituto Progresso Editorial, 1949.

. Teoria da história do Brasil: introdução metodológica. 4 ed. Revista e Ampliada. São Paulo; Brasília: Companhia Editora Nacional, 1978 (Coleção Brasiliana, Biblioteca Pedagógica Brasileira, Série Grande Formato, Vol. 11).

As fontes da história do Brasil na Europa. Rio de Janeiro: Departamento de Imprensa Nacional, 1950.

A pesquisa histórica no Brasil: sua evolução e problemas atuais. Rio de Janeiro: Imprensa Nacional/INL, 1952.

. Capistrano de Abreu e a Historiografia Brasileira. R. IHGB, v. 221, out.-dez., 1953, p. 120-138.

- Historiografia del Brasil. Siglo XVII. Tradução Antonio Alatorre. México: Instituto Panamericano de Geografia e História (Comisión de Historia), 1963. 
. História da história do Brasil. Vol. II - Tomo I. A historiografia conservadora. São Paulo: Companhia Editora Nacional, 1988.

RODRIGUES, Lêda Boechat (org.). Nova correspondência de José Honório Rodrigues. Rio de Janeiro: ABL, 2004.

; MELLO, José Octávio de Arruda. José Honório Rodrigues: um historiador na trincheira. Rio de Janeiro: Civilização Brasileira, 1994.

RÜSEN, Jörn. Razão histórica. Teoria da História I: os fundamentos da ciência histórica. Brasília: Editora UNB, 2001.

História viva. Teoria da História III: formas e funções do conhecimento histórico. Brasília: Editora UNB, 2007.

- Tradition: a principle of historical sense-generation and its logic and effect in historical culture. History and Theory, Theme Issue 51 (Dec. 2012), p. 45-59.

TREVELYAN, George Macaulay. The recreations of an historian. Londres: Nelson \& Sons, 1919.

TROELTSCH, Ernst. Der Historismus und seine problem. Tubingen: J. C. B. Mohr, 1928.

WINDELBAND, Wilhelm. Lehrbuch der Geschichte der Philosophie. Tubingen:

J. C. B. Mohr, 1903. 